CONTRIBUTIONS FROM THE ZOÖLOGICAL LABORATORY OF THE MUSEUM OF COMPARATrVE ZOÖLOGY AT HARVARD COLLEGE E. L. MARk, DrRmeror, No. 24.

\title{
THE OLFACTORY REACTIONS OF THE COMMON KILLIFISH, FUNDULUS HETEROCLITUS (LINN.)
}

\section{G. H. PARKER}

In a paper on the olfactory reactions of fishes published in the eighth volume of the Journal of Experimental Zoölogy (1910), I have attempted to show that the olfactory organs of eatfishes are stimulated by minute amounts of substance emanating from materials that can serve these fishes as food; in other words, that these organs are distance-receptors by which the fishes can scent out their food much as land animals do. A season at the Biological Laboratory of the United States Bureau of Fisheries at Woods Hole, Massachusetts, enabled me to repeat these tests on the common killifish, Fundulus heteroclitus, the results of which are given in this paper. My thanks are due to Dr. F. B. Sumner, Director of the laboratory, for facilities kindly provided, and to Commissioner G. M. Bowers, with whose permission this article is published.

The olfactory apparatus of the killifish consists of a pair of sacs each provided with two apertures, one anterior, and the other posterior. The anterior olfactory aperture is just above the upper lip and dorsal to the angle of the mouth. It is a small roundish opening not unlike one of the pores of the lateral-line system and is on the summit of a low elevation. The posterior olfactory aperture is an elongated slit somewhat dorsal to the anterior limit of the eyeball. The mouth of the posterior aperture is partly occupied by a valve-like fold of skin.

If the quiescent head from a freshly killed Fundulus is examined in water, no motion is observable about the olfactory apertures.

The Jotrana, of Expertmental Zoölogy, Vol. 10 , No. 1

JANUARY, 1911 
Suspended carmine is not carried into them or discharged from them; in other words, there is no evidence of a ciliary current passing through the olfactory sacs such as is so easily demonstrated in the catfish. If a head in which the respiratory movements of the gills are still in progress is examined, well marked currents can be demonstrated in the olfactory organs. Suspended carmine is taken in at the anterior aperture and discharged from the posterior one. With each respiratory movement, the valve in the posterior aperture opens, a small amount of water is discharged, and it then closes. This passage of water through the olfactory apparatus is apparently due to the changes of pressure produced by the rythmic activity of the muscles of the gills probably acting in conjunction with valves within the olfactory sacs. The movement of the valve at the posterior aperture follows exactly that of the respiratory apparatus and its automatic character is obvious from the fact that if an anterior aperture in an active fish is closed by having its walls stitched together so that no current of water can enter the sac at that point, the posterior valve of the same side ceases to pulse, though that of the other side continues in normal activity. If, now, the closed aperture is reopened by removing the stitches, the valve previously quiescent begins again to pulse. Thus, though Fundulus has no continuous current through its olfactory sacs, such as the catfish has, it does have a well-developed intermittent current that is not inappropriately designated as respiratory, though this current is in no direct way concerned with the respiratory function. Apparently, as long as the gill muscles of Fundulus carry out respiratory movements, currents of water run through the olfactory sacs.

As a preliminary test to ascertain whether Fundulus could discover hidden food or not, packets of cotton cloth containing dogfish meat wrapped so as not to be visible, and packets made of nothing but cotton eloth were hung in an aquarium in which there were a number of hungry Fundulus. After the packets had been thoroughly soaked in the seawater, the reactions of the fishes to them were watched. The packets without meat were occasionally approached and siezed, but soon dropped. Those that contained meat were sooner or later surrounded by most of 
the killifish, which carried on a vigorous competition as to which should have possession of the packet. Frequently the first comer would not only seize the packet and tussle with it, but would often attempt to drive off other fish that had approached the region, attracted apparently by the movements of the first fish. These preliminary tests showed quite conclusively that the normal killifish responds very quickly and in a characteristic way to hidden food.

It was also quite evident from these tests that the killifish, in strong contrast with the catfish, uses its eyes as well as its chemical senses, in seeking and retaining its food. If a small piece of dogfish flesh is dropped into an aquarium in which there are hungry killifish, a fish is almost sure to pounce upon the piece and swallow it quickly. This action is so sudden and begins when the fish is at such a distance from the bit of flesh that it is evidently controlled through the eye. That it is not entirely so, however, is seen from the fact that if a small ball of clean filter-paper is thrown into the water, this too is pounced upon and taken into the mouth but soon discharged. Thus the sight of an object must be followed by an appropriate stimulus of smell or taste, if the object is to be swallowed.

It is the eye, in my opinion, that leads killifish to swim to a packet of plain cloth and seize it even though it contains no food. The fact, however, that the fish do not remain about such a packet long shows how clearly they distinguish it from a packet in which meat is hidden and around which they will gather and tussle for long periods of time. The use of the eye in the preliminary steps of the search for food is shown in the amusing habit that these fish have of chasing drops of water down the glass face of an aquarium as though the drops were bits of food. The eye, then, in Fundulus is serviceable in the initial stages of procuring food, but whether the material is to be persistently nibbled and finally swallowed depends, as the preceding test shows, on other senses than sight.

Another feature in the reactions of these fishes that is of importance in connection with their discovery of food and is probably dependent chiefly on sight, is their habit of seeking food 
in schools and not individually. A single fish in an aquarium rarely finds hidden food for the reason that it remains most of the time quietly at the bottom, a position of protection that is assumed by a school of Fundulus when disturbed. If, however, there are a number of fish in the aquarium, they soon rise to the higher water, play about, and thus have a much better chance to run across traces of food. For this reason, I have generally not experimented with single fish, but with small groups of at least five or six.

The part played by the olfactory organs in reactions to hidden food can be determined by first eliminating these organs and then testing the fishes. The olfactory apparatus can be rendered inoperative by cutting the olfactory tracts in a position where they are easily accessible as, for instance, between the eyes. In this situation a small incision can be made through the thin bony roof of the skull and the two tracts can be cut by a single movement of a narrow blade. The first operations of this kind that I carried out were done under ether, but subsequent tests on normal fishes showed that etherization of itself, i.e. without any operation, left the fishes in such a condition that they could not distinguish for a number of days packets of cloth without inclosed meat from those that included meat, and, therefore, I was driven to carry out these operations without the use of an anesthetic. Twenty-four hours after such an operation, the fish were fully active, took food, and in all obvious ways seemed normal. When two packets of cloth one with dogfish meat hidden in it and the other without this food, were suspended in the aquarium in which the operated fishes were, these animals nibbled temporarily both packets in a way that made it impossible for an uninformed observer to distinguish one packet from the other. When these two packets were transferred to an aquarium of normal fish, the one containing the food was soon surrounded by a vigorously contesting assembly of fishes, whereas the packet without food was only occasionally nibbled. The evidence from these experiments favors the view that the olfactory organs are necessary to Fundulus in sensing hidden food. The severity of the operations, however, makes this evidence not wholly conclusive. 
In order to carry out tests against which the objection could not be raised that the results might be due to the shock of cutting nerves rather than to the loss of a sense organ, the following procedure was employed. By taking two stitches of very fine silkthread one on either side of the anterior olfactory aperture, it was comparatively easy to close this aperture and thus to prevent any passage of water through the olfactory sacs. Killifish, which previous to the operation gave markedly different and characteristics reactions to the two classes of cloth packets already described, reacted to both kinds of packets after their anterior olfactory apertures were closed, as they had previously done to the packets that contained no food. That this reaction was not to be directly attributed to the operation of stitching up the apertures, was demonstrated in two ways. If, after the stitches were taken, the thread was not drawn up and tied so as to close the aperture, but the ends were allowed to remain free, the fish would react as normal fish do to the two classes of cloth packets, thus showing that the mechanical injury due to the stitches themselves did not influence the fish in any essential way. Further, if fishes whose anterior olfactory apertures had been closed by stitching and tying and whose discrimination for the two classes of packets had thereby been lost, had their olfactory apertures reopened by cutting and removing the thread, they very soon regained their capacity to distinguish packets with food from those without food; in other words, they scon returned to the condition of normal fishes. For these reasons, I believe that stitching up the anterior olfactory aperature is in itself not a disturbing operation for the fish and that the loss of the ability to recognize the presence of hidden food under these circumstances, is in reality due to the loss of the olfactory function. I, therefore, conclude that Fundulus heteroclitus, like the catfish, uses its olfactory apparatus as an organ with which to scent its food; i. e., its olfactory apparatus is a chemical distance-receptor of very considerable importance in its daily activities. 